\title{
Relationship of Slightly Limited Mandibular Movements to Temporomandibular Disorders
}

\author{
Robert CELIC \\ Vjekoslav JEROLIMOV \\ Dubravka KNEZOVIC ZLATARIC
}

Department of Prosthodontics, School of Dental Medicine, University of Zagreb, Zagreb, Croatia

\begin{abstract}
Mandibular movements have been analyzed extensively in the past for prosthodontic reasons, and more recently to study the function of the masticatory system. This study investigated the range of mandibular movements in a young male population, and analyzed the difference in range of mouth opening, right and left lateral movements, and protrusive movement between asymptomatic subjects (control group) and patients with clinical diagnoses of temporomandibular disorders. A total of 180 subjects, aged 19-28 years, were included in the study. The TMD sample comprised 90 patients ( 30 patients with muscle disorders; 30 patients with disc displacement with reduction; 30 patients with muscle disorders and disc displacement with reduction) and was compared with 90 healthy control subjects. All participants were evaluated by the attending dentist at baseline with a complete physical examination and history questionnaire, which included the Research Diagnostic Criteria for Temporomandibular Disorders Axis I measures. Analysis of variance (ANOVA) showed significant differences in ranges of mandibular movements between and within the groups of healthy control subjects and patients with muscle and temporomandibular joint disorders. It is suggested that there are differences in the range of mandibular movements that clearly separate asymptomatic subjects and patients with temporomandibular disorders in this young male population.
\end{abstract}

Key Words: mandibular movements, temporomandibular disorders (TMD).

\section{INTRODUCTION}

Temporomandibular disorders (TMD) are recognized as the most common chronic orofacial pain condition confronting dentists and other health care providers. Recent epidemiologic studies have generally found significantly more frequent and more severe TMD signs and symptoms (pain and tenderness in the temporomandibular joints (TMJ) and masticatory muscles, sounds in the TMJ, and limitation or other disturbances of mandibular movement) in women than in men (1). Limited movement of the mandible may reflect a disorder of the temporomandibular joint and masticatory muscles. To determine limited movement, a normal range of movement must have been established $(2,3)$.

In physical examination for temporomandibular disorders, measurement and recording of mandibular movements should be completed for opening, and lateral and protrusive movements. The quality and symmetry of jaw movement should be noted and diagrammed
(4). Dworkin et al. (5) reported significant differences in the amplitude of jaw opening between TMD patients and control subjects. In their study, Hesse et al. (6) compared active maximum mouth opening, and temporomandibular stiffness values of three temporomandibular disorder patient subgroups and a control group. The temporomandibular disorder patient subgroups consisted of myogenous pain patients and arthrogenous pain patients with a "closed lock" and arthrogenous pain patients without a "closed lock." Both myogenous patients and the "closed lock" patients showed great differences for all parameters. Some studies have also suggested significant differences in mouth opening between asymptomatic subjects and patients with temporomandibular disorders (7-9).

The aim of this study was to investigate the range of mandibular movements (mouth opening, right and left lateral movement, and protrusive movement) and to analyze the differences between the range of mandibular movements in asymptomatic subjects and patients with an established clinical diagnosis of temporoman-

Correspondence: Robert Celic DDS, PhD, Department of Prosthodontics, School of Dental Medicine, University of Zagreb, Gunduliceva 5, 10000 Zagreb, Croatia. e-mail: <robert.celic@zg.htnet.hr> or <celic@sfzg.hr> 
dibular disorders in a young male population.

\section{MATERIAL AND METHODS}

A total of 180 subjects participated in the present study: 90 TMD patients (30 patients with muscle disorders; 30 patients with disc displacement with reduction; 30 patients with muscle disorders and disc displacement with reduction) and 90 healthy control subjects. Study participants were recruited from patients referred for treatment to the Department of Prosthodontics, School of Dental Medicine, University of Zagreb, Croatia. All subjects were men in the age group of 19 to 28 years. Subjects in the control group (with a mean age of 21.4 years) were group-matched with subjects in the TMD group (with a mean age of 21.3 years) to achieve a similar age distribution. The individuals in the control group were randomly selected from the same community sample of young male adults as the TMD group.

Research Diagnostic Criteria for Temporomandibular Disorders (RDC/TMD) uses a dual axis system for diagnosing and classifying TMD patients (10). Axis I assigns physical diagnoses of the most commonly occurring masticatory muscles and/or TMJ disorders. According to these criteria, the patients of the study were divided into three groups: muscle disorder (MD), disc displacement with reduction (DDR), and disc displacement with reduction associated with muscle disorder (DDR + MD).

Measurement of mouth opening: A millimeter ruler was placed at the incisal edge of the maxillary central incisor that is the most vertically oriented and measured vertically to the labioincisal edge of the opposing mandibular incisor. The amount of vertical incisor overlap (the distance between the incisal edges of the upper and lower central incisors) was added to each of these measurements to determine the actual amount of opening. Measurement of lateral movements: The subject opened his mouth slightly (physiologic rest position) and moved the mandible as far as possible toward the right or left. Using a millimeter ruler we measured from the midline labioincisal embrasure of the maxillary central incisors to the labioincisal embrasure of the mandibular incisors. Measurement of protrusive movement: The initial position was the physiologic rest position from which the subject moved the mandible anterior without tooth contact. The distance from the incisal edge of maxillary central incisor to the incisal edge of mandibular central incisor was measured in the maximal protruded position. The horizontal overlap (the distance between the incisal edges of the upper central incisor and the labial surface of the lower central incisor) was also measured and then added to the distance between the upper labial surface and the lower incisal edge $(3,10)$.

Descriptive statistics (arithmetic means, standard deviation, standard error, and minimum and maximum values) were used for analysis of range of mandibular movements. Analysis of variance (ANOVA) was used to test for differences in the range of mandibular movements between asymptomatic subjects and patients with the muscle and temporomandibular joint disorders (disc displacement with reduction). Statistical significance was set at $p<0.05$. A very good to excellent reproducibility has been reported for registration of jaw measurements (11).

\section{RESULTS AND DISCUSSION}

Muscle (extracapsular) and temporomandibular joint (intracapsular) disorders are often causes of limited mandibular movements. Previous studies of asymptomatic subjects demonstrated that $1.2 \%$ of young adults and $15 \%$ of an elderly group opened their mouth less than $40 \mathrm{~mm}$. Less than $40 \mathrm{~mm}$ seems to represent a reasonable point of incisor separation on maximal opening, but one should always consider the patient's age and body size (3).

The average and range of mandibular movements (mouth opening, right and left lateral movements, and protrusive movement) among asymptomatic subjects and patients with clinical diagnoses of TMD are shown in Table 1. Mouth opening at the incisors ranged from 35 to 61 millimeters (mean $47.8 \mathrm{~mm}$ ) in asymptomatic and TMD patients groups. The range of the right lateral movement in these subjects ranged from 2 to $14 \mathrm{~mm}$ (mean $7.7 \mathrm{~mm}$ ), while the range of the left lateral movement ranged from 3 and $14 \mathrm{~mm}$ (mean $7.7 \mathrm{~mm}$ ). The range of protrusive movement in the study's subjects ranged from 2 to $11 \mathrm{~mm}$ (mean 5.7 $\mathrm{mm}$ ) in both groups. These findings were in accordance with previous clinical studies $(5,12-16)$.

Results of ANOVA are presented in Table 2. Statistically significant or clinically meaningful differences were observed between and within the groups of asymptomatic subjects and patients with muscle and 
TMJ disorders. Most frequently, the studies reported in the literature evaluated the range of maximum mouth opening and the possible association with TMD. The mean mouth opening of $50 \mathrm{~mm}$ could be regarded as normal, and mandibular movements were clinically similar in asymptomatic subjects and in patients with disc displacement. However, several studies $(8,17,18)$ have suggested significant differences in mouth opening between asymptomatic groups and groups with muscle and TMJ disorders. The findings of this study also demonstrated meaningful clinical differences between TMD patients and healthy controls at measurement of maximum mouth opening ( $\mathrm{p}=0.016)$.

Studies evaluating lateral and protrusive move-

Table 1. Range of the mandibular movements in relation to the established clinical diagnoses of TMD.

\begin{tabular}{lccccc}
\hline \multicolumn{1}{l}{} & Mean & SD & SE & Min & Max \\
\hline Mouth opening & & & & & \\
Control & 49.89 & 5.27 & 0.56 & 40 & 61 \\
MD & 46.47 & 5.10 & 0.75 & 35 & 56 \\
DDR & 46.97 & 5.05 & 0.71 & 36 & 57 \\
DDR+MD & 47.93 & 5.60 & 1.02 & 37 & 58 \\
Total & 47.82 & 5.26 & 0.41 & 35 & 61 \\
Right lateral movement & & & & \\
Control & 8.36 & 2.46 & 0.26 & 4 & 14 \\
MD & 7.10 & 2.06 & 0.38 & 2 & 12 \\
DDR & 7.10 & 2.45 & 0.45 & 3 & 12 \\
DDR+MD & 6.87 & 2.19 & 0.40 & 3 & 11 \\
Total & 7.69 & 2.43 & 0.18 & 2 & 14 \\
Left lateral movement & & & & \\
Control & 8.34 & 2.49 & 0.26 & 3 & 14 \\
MD & 7.47 & 2.03 & 0.37 & 3 & 12 \\
DDR & 7.00 & 2.08 & 0.38 & 3 & 11 \\
DDR+MD & 6.97 & 2.25 & 0.41 & 3 & 11 \\
Total & 7.74 & 2.38 & 0.18 & 3 & 14 \\
Protrusive movement & & & & \\
Control & 6.16 & 1.90 & 0.20 & 3 & 11 \\
MD & 5.57 & 1.70 & 0.31 & 2 & 8 \\
DDR & 5.17 & 1.62 & 0.30 & 3 & 9 \\
DDR+MD & 4.87 & 1.61 & 0.29 & 2 & 8 \\
Total & 5.68 & 1.84 & 0.14 & 2 & 11 \\
\hline
\end{tabular}

$\mathrm{SD}=$ standard deviation; $\mathrm{SE}=$ standard error. Control $=$ asymptomatic subjects $(\mathrm{N}=90) ; \mathrm{MD}=$ muscle disorder $(\mathrm{N}=30)$; $\mathrm{DDR}=$ disc displacement with reduction $(\mathrm{N}=30)$; $\mathrm{DDR}+\mathrm{MD}=$ disc displacement with reduction and muscle disorder $(\mathrm{N}=30)$. Total: $\mathrm{N}=180$. ments in asymptomatic and symptomatic subjects have suggested varied results. Piehslinger et al. (19) reported the difference in the mean lateral movements in male volunteers (right - $11.1 \mathrm{~mm}$; left - 11.12) and male patients with temporomandibular disorders (right $9.54 \mathrm{~mm}$ : left - 9.37). Gsellman et al. (20) used electronic axiography and found significant differences in length and form of protrusive movements of left and right joints between asymptomatic subjects and patients with TMD. However, the results of this study suggested differences between the ranges of right $(\mathrm{p}=0.003)$, left $(\mathrm{p}=0.006)$ lateral and protrusive movements $(\mathrm{p}=0.002)$ between TMD patients and controls. Because impairment of mandibular movement is one of the signs of many types of TMD, it is not surprising that quantification of mandibular movement has been considered important.

Mandibular movement measurements can also be determined with electronic jaw-tracking systems; however, there are no scientific data to demonstrate that these techniques are any more useful in measuring mandibular function than a traditional millimeter ruler. With this in mind, cost efficiency should be considered.

Table 2. ANOVA of ranges of the mandibular movements between and within groups of asymptomatic subjects and patients with TMD diagnoses.

\begin{tabular}{lccccc}
\hline & $\begin{array}{c}\text { Sum of } \\
\text { Squares }\end{array}$ & df & $\begin{array}{c}\text { Mean } \\
\text { Square }\end{array}$ & F & p \\
\hline Mouth opening & & & & & \\
$\quad$ Between groups & 310.5 & 3 & 103.5 & & \\
Within groups & 5151.2 & 176 & 29.3 & 3.5 & 0.016 \\
Total & 5461.7 & 179 & & & \\
Right lateral movement & & & & & \\
Between groups & 81.1 & 3 & 27.1 & & \\
Within groups & 975.5 & 176 & 5.5 & 4.9 & 0.003 \\
Total & 1056.6 & 179 & & & \\
Left lateral movement & & & & & \\
Between groups & 69.5 & 323.2 & & & \\
Within groups & 942.8 & 176 & 5.4 & 4.3 & 0.006 \\
Total & 1012.2 & 179 & & & \\
$\begin{array}{l}\text { Protrusive movement } \\
\text { Between groups }\end{array}$ & 48.5 & 3 & 16.2 & & \\
Within groups & 554.8 & 176 & 3.2 & 5.1 & 0.002 \\
Total & 603.3 & 179 & & & \\
\hline
\end{tabular}

$\mathrm{df}=$ degree of freedom; $\mathrm{F}=$ distribution; $\mathrm{p}=$ probability. 
Thus, the use of jaw-tracking devices at this time is not recommended for the routine mandibular function measurements and diagnosis of temporomandibular disorders or other painful orofacial problems.

In conclusion, evaluation of mandibular patterns is recommended as diagnostic criteria for all classifications of temporomandibular disorders. These disorders are characterized by restrictions, deviations, and limitations of these patterns, including range of motion, frontal deviations, limited lateral extrusion, etc. The results of this study were in accordance with similar clinical studies in which the differences in the range of mandibular movements clearly separated asymptomatic subjects and patients with temporomandibular disorders. Clinicians should be reassured that the use of the patient history and a physical examination to detect and classify temporomandibular disorders still represents the highest standard of patient care.

\section{RESUMO}

Movimentos mandibulares têm sido extensivamente analisados no passado por razões protéticas, e mais recentemente para analisar a função do sistema mastigatório. Este estudo investigou a amplitude dos movimentos mandibulares em uma população masculina de jovens, e analizou a diferença na amplitude de movimento mandibular em movimentos laterais direito e esquerdo e em movimentos protrusivos, entre pacientes assintomáticos (grupo controle) e pacientes com diagnóstico de desordem temporomandibular. Um total de 180 pacientes, com idades de 19-28 anos, foram incluídos neste estudo. A amostra com DTM consiste em 90 pacientes (30 pacientes com disfunção muscular; 30 pacientes com deslocamento de disco com redução; 30 pacientes com disfunção muscular e deslocamento de disco com redução) e foi comparada com 90 pacientes saudávies no grupo controle. Todos os pacientes foram avaliados por um dentista com um exame físico completo e anamnese, que incluiu medidas de "Research Diagnostic Criteria for Temporomandibular Disorders Axis I". A análise de variância (ANOVA) mostrou diferenças significantes na amplitude de movimentos entre e dentro do grupo de pacientes saudáveis do grupo controle e pacientes com desordens temporomandibulares e de disco articular. Encontrouse diferenças significantes na amplitude dos movimentos mandibulares que separaram os pacientes assintomáticos e pacientes com desordens temporomandibulares em uma população masculina de jovens.

\section{REFERENCES}

1. Carlsson GE. Epidemiology and treatment need for temporomandibular disorders. J Orofac Pain 1999;13:232-237.

2. Ash MM, Ramfjord SP. Occlusion. 4th edn. Philadelphia: WB
Saunders; 1995.

3. Okeson JP. Management of Temporomandibular Disorders and Occlusion. 4th edn. St Louis: Mosby Year Book; 1998.

4. Clark GT, Seligman DA, Solberg WK, Pullinger AG. Guidelines for the examination and diagnosis of temporomandibular disorders. J Craniomandib Disord Facial Oral Pain 1989;3:7-14.

5. Dworkin SF, Huggins HG, LeResche L, Von Korff MR, Howard J, Truelove E, Sommers E. Epidemiology of signs and symptoms in temporomandibular disorders: clinical cases and controls. J Am Dent Assoc 1990;120:273-281.

6. Hesse JR, Naeije M, Hansson TL. Craniomandibular stiffness in myogenous and arthrogenous CMD patients, and control subjects: a clinical and experimental investigation. J Oral Rehabil 1996;23:379-385.

7. Tallents RH, Katzberg RW, Murphy W, Proskin H. Magnetic resonance imaging findings in asymptomatic volunteers and symptomatic patients with temporomandibular disorders. J Prosthet Dent 1996;75:529-533.

8. Miller VJ, Bookhan V, Brummer D, Singh JC. A mouth opening index for patients with temporomandibular disorders. J Oral Rehabil 1999;26:534-537.

9. Capurso U. Clinical aspects of craniomandibular disorders. II. Symptom profiles of subgroup. Minerva Stomatol 1996;45:321330.

10. Dworkin SF, LeResche L. Research Diagnostic Criteria for Temporomandibular Disorders: Review, Criteria, Examinations and Specifications, Critique. J Craniomandibular Disord Facial Oral Pain 1992;6:301-355.

11. Dworkin SF, LeResche L, DeRouen T, Von Korff M. Assessing clinical signs of temporomandibular disorders: Reliability of clinical examiners. J Prosthet Dent 1990;63:574-579.

12. Agerberg G. Maximal mandibular movements in young men and women. Swed Dent J 1974;67:81-100.

13. Pullinger AG, Seligman DA, Solberg WK. Temporomandibular disorders. Part I: Functional status, dentomorphologic features, and sex differences in a population. J Prosthet Dent 1988;9:228235.

14. Kang, JH, Chung SC, Friction JR. Normal movements of mandible at the mandibular incisor. J Prosthet Dent 1991;66:687692.

15. Piehslinger E, Celar A, Futter K, Slavicek R. Orthopedic jaw movement observations. Part I: Determination and analysis of the length of protrusion. J Craniomandib Practice 1993;11:113-117.

16. Woelfel JB, Scheid RC. Dental Anatomy: Its Relevance to Dentistry. $6^{\text {th }}$ ed., Philadelphia: Lippincott Williams \& Wilkins, 2002. 301.

17. Roberts CA, Tallents RH, Espeland MA, Handelman SL, Katzberg RW. Mandibular range of movement versus arthrographic diagnosis of the temporomandibular joint. Oral Surg Oral Med Oral Pathol 1985;60:244-251.

18. Miller VJ, Karic VV, Myers SL, Exner HV. Myogenous temporomandibular disorder patients and the temporomandibular opening index. J Oral Rehabil 2000;27:720-722.

19. Piehslinger E, Celar A, Schmid-Schwap M, Slavicek R. Orthopedic jaw movement observations. Part III: The quantitation of mediotrusion. Cranio 1994;12:33-37.

20. Gsellmann B, Schmid-Schwap M, Piehslinger E, Slavicek R. Lengths of condylar pathways measured with computerised axiography (CADIAX) and occlusal index in patients and volunteers. J Oral Rehabil 1998;25:146-152. 